\title{
HAPLODIPLOIDY IN THE OXYURIDA: DECOUPLING THE EVOLUTIONARY PROCESSES OF ADAPTATION AND SPECIATION
}

\author{
M. L. ADAMSON
}

SUMMARY

Host distribution and life history variation in the Oxyurida are discussed in the context of haplodiploidy. The Oxyurida have the broadest host distribution of any zooparasitic nematode group but have retained a virtually unchanged life cycle. Like other haplo- diploids, oxyuridans have life histories that maintain viscous population structures. It is postulated that this has facilitated speciation but may have discouraged major evolutionary inovation in the group.

RÉsumé : L'haplodiploïdie des Oxyurida : analyse des processus évolutifs de spéciation et d'adaptation.

Le spectre d'hôtes et les particularités biologiques des Oxyures sont analysés dans le contexte de l'haplodiploïdie. Les Oxyures ont le spectre d'hôtes le plus vaste de tous les Nématodes, mais le cycle biologique est uniforme. Les Oxyures, comme d'autres espèces haplodiploïdes, ont des cycles évolutifs qui maintiennent des populations stables. Il est vraisemblable que ces facteurs ont facilité la spéciation mais ont empêché des changements majeurs dans la biologie du groupe.

\section{INTRODUCTION}

The parasitic Nematoda represent descendants of many independently derived parasitic lines (Adamson, 1986, $1989 b$ ). The Oxyurida, or pinworms, is one of several major parasitic lineages that have Rhabditida as a free-living outgroup. Unlike their sister lineages (Ascaridida, Spirurida, Strongylida), pinworms have a relatively invariant life cycle; perhaps because of this their ecology has received limited attention. Recent studies (reviewed in Adamson, 1984, 1989a) show that they are haplodiploid, i.e. males derive from unfertilized eggs and are haploid, whereas females derive from fertilized eggs and are diploid. This form of reproduction occurs in monogonant rotifers, most Acari (although not Metastigmata, or ticks), and several insect orders (Thysanoptera, Hymenoptera, two subfamilies of Coccoidea, and two unrelated groups of Coleoptera) (see White, 1973). Haplodiploidy has attracted much attention in the last 25 years because haplodiploid species (particularly Hymenoptera) provide exciting models in behavioral ecology. Life history variation in the Oxyurida shows much convergence with other haplodiploid groups. This review presents theses variations and suggests that much of the evolutionary ecology of pinworms may be explained by factors associated with haplodiploid reproduction.

Department of Zoology, University of British Columbia, Vancouver, B. C., Canada V6T 2A9.

\section{HOST DISTRIBUTION}

Pinworms have the broadest host distribution of any parasitic nematode group. The 164 genera are about evenly divided between invertebrate (essentially arthropod) and vertebrate hosts (tables I and II). Monophyly of the parasites of arthropods (placed in the Thelastomatoidea) is suggested by their unique, highly contracted infective stage (Adamson and Clease, 1989). Monophyly of the pinworms of vertebrates (comprising the Oxyuroidea) is evidenced by the fusion of outer cephalic papillae. Further taxonomic details can be found in Adamson (1989a) and Petter and Quentin (1976).

Diplopods, cockroaches and passalid beetles are the most

TABLE I. - Number of Thelastomatoidea genera (number of genera unique to host group in parentheses) and species occurring in various arthropod host groups.

\begin{tabular}{lcc}
\hline \multicolumn{1}{c}{ Hostgroup } & $\begin{array}{c}\text { Genera } \\
\text { (unique) }\end{array}$ & $\begin{array}{c}\text { Species } \\
\text { (in unique genera) }\end{array}$ \\
\hline $\begin{array}{l}\text { Diplopoda } \\
\text { Blattoida }\end{array}$ & $14(5)$ & $63(7)$ \\
Orthoptera & $28(20)$ & $89(50)$ \\
Coleoptera & $14(13)$ & $37(36)$ \\
$\quad \begin{array}{l}\text { Passalidae } \\
\text { Hydrophilidae }\end{array}$ & $21(21)$ & $76(76)$ \\
$\quad$ Scarabaeidae & $6(6)$ & $27(27)$ \\
$\begin{array}{l}\text { Diptera } \\
\quad \text { Tipulidae }\end{array}$ & $11(3)$ & $41(3)$ \\
\hline
\end{tabular}


TABLE II. - Number of Oxyuroidea genera (number of genera unique to host group in parentheses) and species occurring in various vertebrate host groups.

\begin{tabular}{lcc}
\hline Hostgroup & $\begin{array}{c}\text { Genera } \\
\text { (unique) }\end{array}$ & $\begin{array}{c}\text { Species } \\
\text { (in unique genera) }\end{array}$ \\
\hline Teleostei & $5(5)$ & $6(6)$ \\
Amphibia & $5(3)$ & $22(11)$ \\
Squamata & $11(5)$ & $136(33)$ \\
Testudinidae & $7(4)$ & $54(13)$ \\
Marsupiali & $3(3)$ & $4(4)$ \\
Dermoptera & $1(1)$ & $9(9)$ \\
Primata & $9(9)$ & $38(38)$ \\
Rodentia & $25(25)$ & $144(144)$ \\
Ungulata & $3(3)$ & $9(9)$ \\
Lagomorpha & $6(6)$ & $32(32)$ \\
Aves & $2(2)$ & $6(6)$ \\
\hline
\end{tabular}

important arthropod hosts. Although the fauna of passalid beetles outnumbers that of diplopods in species and genera, it comprises a specialized family, the Hystrignathidae. The fauna of diplopods and cockroaches is vastly more diverse. Lizards, rodents and, to a lesser extent tortoises, are the most important host groups in the Oxyuroidea.

It is generally held that the Oxyurida arose in arthropods and later spread to vertebrate hosts. The phylogeny, however, composed one group in arthropods and another in vertebrates, does not unambiguously point to arthropods as the primitive host group. Nevertheless, aspects of the host distribution suggest that the fauna in arthropods is older than that in vertebrates. Nematode parasitism probably arose in the terrestrial environment (Anderson, 1984). The Oxyurida is well represented in ancient terrestrial arthropod groups such as the Diplopoda and Blattoid insects; there is no evidence that the group is paleoendemic in tetrapods. Pinworms are virtually absent in birds, crocodiles and amphibians; they occur in turtles but only in the relatively recent terrestrial tortoises. The Oxyuroidea of vertebrates may be descendants of a line that persisted in early mammals and spread later to certain lizard, turtle and amphibian groups.

Hosts to pinworms are ecologically similar in that the posterior gut is modified to form a sort of fermentation chamber. Arthropod hosts to pinworms tend to be colonizers of habitats afforded by secondary succession (rotting logs, late succession ponds, etc.) where they feed on decaying vegetation. Vertebrate hosts are herbivorous or omnivorous. The lizards are perhaps an exception in this regard, since they are largely insectivorous. However, strictly carnivorous lizards such as Varanidae are not infected and pinworms are most common in the more omnivorous forms such as iguanids and agamids.

\section{HOST SPECIFICITY}

Paradoxically, the host distribution of the Oxyurida, although phylogenetically broad, belies an extremely narrow specificity of individual species. Whereas most parasitic nematodes are specific at most to the level of host genus or so, oxyuridan species are commonly restricted to individual host species. Although little is known of how specificity is maintained in individual species, Inglis $(1968,1971)$ suggests there is a strong ecological component in to the specificity of Parathelandros spp. parasiting West Australian frogs. Thus, sympatric frog species often harbor the same parasites. Similarly, Gyrinicola spp. occur in tadpoles throughout the world but are not specific even to host family: G. batrachiensis occurs in three families (Hylidae, Ranidae and Bufonidae), G. tba in five families (Pelobatidae and Discoglossidae in addition to the three previously mentioned) of Anura. Nevertheless, closely related hosts may harbor distinct faunae even in apparent sympatry. For example, sympatric sister species of agamid lizards, Agama adramitana and A. yemenensis, harbor entirely distinct Oxyuridan faunae (Adamson and Nasher, 1984, 1985). Cross transmission studies on individual species could be particularly revealing with respect to the nature of specificity in this group.

This strong specificity is reflected in the fact that parasites of particular host groups tend to be closely related. Extreme examples of this are seen in passalid and hydrophilid beetles, which harbor unique families, but similar specificity occurs in most vertebrate host groups (table II). This sort of pattern is expected to prevail is specificity is largely the result of ecological factors such as host feeding habits and localized transmission. Parasites tend to speciate with the host group, but occasionnaly are able to infect and, if conditions are suitable, establish new evolutionary lines in unrelated hosts.

\section{VARIATIONS IN PINWORM ECOLOGY}

Adult pinworms occur in the posterior gut of their host where they feed on the bacterial flora. Females deposit eggs which are passed to the external environment in the host faeces; there is one molt in ovo prior to development of the infective late second stage (Adamson and Clease, 1989; Adamson, 1989a). Transmission occurs when infective eggs are ingested by a suitable host; the molt to the third stage precedes hatching and worms develop through third- and fourth-stage to adulthood without leaving the intestinal lumen.

\section{Dispersal}

Most nematodes have resistant free-living stages or intermediate hosts which disperse them in time and/or space, and encourage outcrossing. Pinworms have direct life cycles and an egg which is highly susceptible to dessication. In many species, infectivity of eggs can be maintained only within a narrow temperature range. This means that dis- 
persal of pinworms depends on stages within the host and therefore on the host themselves. Since many hosts to pinworms are organisms of limited vagility (diplopods, cockroaches, tortoises, rodents, etc.), pinworms have little ability to disperse and transmission commonly occurs within host family groups or extremely local aggregations. They tend towards a clonal population structure.

\section{Aggregation of Egg Output and Sibmating:}

The pattern of egg deposition in pinworms further structures pinworm populations. Thus in many pinworms, eggs are not deposited one at a time but in aggregated groups. Many members of the Chitwoodiellidae deposit strings of eggs attached to each other by polar threads. Gryllophila spp. deposit egg strings encased in uterine secretions and in Cameronia spp eggs are attached to one another by their surface coat. In some pinworms of lizards and amphibians, gravid females pass out of the host and funstion as oothecae. In most pinworms of mammals, females deposit eggs in a single mass around the anus (peri-anal egg deposition).

However it occurs, aggregation of egg output ensures that when hosts become infected they do so with several individuals as a time, all progeny of a single female. Sibmating is probably a frequent component of pinworm life histories, as it is in most other haplodiploids (Hamilton, 1967; Borgia, 1980).

\section{Autoinfection and Mother-son Mating}

One of the disadvantages of having separate sexes is that two individuals are needed to colonize a habitat. Haplodiploids can get around this because isolated females can colonize habitats if they survive to mate with their parthenogenetically-produced male progeny. Pinworms occur in the host gut and typically eggs pass to the external environment before they can become infective. Matings between mother and son would not be expected to occur frequently. However, autoinfective eggs have arisen in at least three independent lines; these eggs hatch at deposition and allow progeny to develop in the same host as the mother making mother-son matings possible.

In Alaeuris spp. and Tachygonetria vivipara there are two types of females: oviparous females produce typical thick-shelled eggs which pass to the external environment to become infective, and ovoviviparous females produce thin-shelled autoinfective eggs. In Gyrinicola spp., individual females produce two egg types in separate horns of the reproductive system. Nevertheless, one egg type predominates in a given female and one can speak of essentially oviparous or ovoviviparous forms. Furthermore there is an alternation of generations such that females that develop from thick-shelled eggs produce predominantly thin-shelled eggs whereas those that develop from thin-shelled eggs produce almost exclusively thick-shelled eggs.
Two further details in the biology of these species makemother-son matings likely. Firstly, males are progenetic, i.e. they develop more rapidly than females, reaching sexual maturity in half the time; this makes it more likely that females can survive to mate with their progeny. Secondly, most of the thick-shelled eggs are diploid; thus, the initial colonizing generation commonly consists exclusively of females which must be inseminated by their parthenogenetically-produced male progeny. The ability of isolated females to colonize hosts using mother-son matings is offset by the fact that this form of colonization involves a delay in reproduction waiting for males to mature. This delay is minimized by the sexual precocity of male pinworms but female biased sex ratios are advantageous only as long as there is an appreciable probability of males being isolated in hosts without females. As sex ratios become increasing by biased towards females, and/or mean abundance increases, the evolutionarily stable sex ratio approaches 1:1. Analogous life histories involving mother-son mating and skewed sex ratios are known in most haplodiploid groups and the reader is referred to Borgia (1980) for a review.

\section{Interference Competition}

Some pinworms of cockroaches and beetles exhibit strong interference competition such that, regardless of how many eggs a host ingests, the mature parasite population consists of one male and one female. Zervos $(1988 a, b)$ described this phenomenon in several parasites of New Zealand cockroaches and we have observed it in Leidynema appendiculata and Blatticola blattae in the American and German cockroaches (Periplaneta americana and Blatella germanica) and in Zonothrix columbianus in the hydrophilid beetle, Tropisternus columbianus. That the competition is not a direct one for some host resource is indicated by the fact that males, less than a tenth the size of females, exhibit the most extreme competition. How it occurs is unknown but Zervos suggests a sex-specific anthelminthic might be released by the most rapidly developing worms. It is not known how sex specificity would be maintained. The other way to look at the phenomenon is as altruistic suicide. This requires that the interacting worms be clonally related. Our unpublished results show that competing worms are eliminated whether or not the inoculum consists of full sibs and thus do not support the suicide hypothesis.

This sex-specific competition has a counterpart in other haplodiploids. For example Hamilton (1967) discussed species which deposit their eggs in clusters. Males hatch before females and the first males to hatch kill other males from the same clutch. By this means they secure all females in the clutch as their mates.

\section{Male Progenesis and Traumatic in semination}

A near ubiquitous feature of pinworms is that males are smaller than and develop more rapidly than females. 
Adult males generally retain juvenile characteristics and are described as neotenic by many workers. We prefer the term progenetic, reserving neoteny for those situations where somatic development is retarded. In progenesis, sexual maturation is accelerated (see Gould, 1977).

The selective advantage of progenetic males is evident in Gyrinicola spp. where females often have no mate with their sons. Similarly in species which exhibit intraspecific competition, the first male to mature can eliminate its competitors and secure hegemony over females in the host. However, male progenesis occurs very widely in the group (and in other haplodiploid groups) and may be a simple consequence of haploidy that proves adaptive in certain life histories.

Male progenesis may have been a pre-adaptation to traumatic insemination, whereby males inseminate immature females by puncturing the cuticle and introducing sperm into the pseudocoel before the vulva becomes patent. This phenomenon has arisen independently in the subfamilies Oxyurinae and the Syphaciinae (see Hugot et al., 1982; Hugot, 1984, 1986). In all species in which it occurs females deposit eggs around the anus and hosts therefore infect themselves simultaneously with cohorts of worms. Severe competition among males to be the first to mate presumably set the stage for the development of traumatic insemination. Encounters between adult males and fourth stage females would have been common because of the progenetic development of males, and any male that succeeded in inseminating females in the fourth stage would have been at a great selective advantage.

Traumatic insemination, although uncommon, has been reported in haplodiploid rotifers and Hymenoptera. It is presumably an extension of male progenesis and life histories that involve a developmental race among males to be first to mate.

\section{Thelytoky}

Thelytoky (parthenogenetic production of females) is extremely rare in nematodes. Obligate (as opposed to cyclic) thelytoky occurs in polyploid strains of some Tylenchoidea but certain pinworms provide our only other substantiated example of this phenomenon. Thelytoky in pinworms has been documented only in strains of $G$. batrachiensis parasitizing anuran hosts that have brief tadpole stages; the form of thelytoky is apomixis, where females produce offspring by a mitosis-like mechanism. Gyrinicola spp. cannot persist in frogs after metamorphosis and apomictic strains, presumably derived from haplodiploid parental stocks in Rana clamitans or $R$. catesbeiana are selected for in hosts with ephemeral tadpole stages, where rapid reproduction is essential (Adamson, 1981 $a, b$ ). Apomicts do not need to find a male to reproduce. Furthermore, the ovary responsible for production of autoinfective eggs in haplodiploids is non-functional in apomicts.
Thelytoky is sporadically distributed in all haplodiploid groups. This probably reflects the frequency with which haplodiploids depend on colonization of ephemeral habitats in their life histories. In an earlier article (Adamson, 1984) I suggested that thelytokous strains may be selected over sexual strains where extreme inbreeding occurred; some of the presumed advantages of sexual reproduction are lost under conditions of high inbreeding. However, haplodiploid (i.e. sexual) reproduction persists in the face of extremely high levels of inbreeding. Thelytoky is probably selected more for its colonization possibilities than for its the fact that it obviates homozygosity.

\section{DISCUSSION}

This review of life history variations in the Oxyurida reveals that they have many ecological similarities to other haplodiploid taxa. A persistent component of haplodiploids is an elevated level of inbreeding. They tend to be creatures of low vagility with viscous population structures.

The reason haplodiploids tend towards structured populations is probably twofold. Firstly, haplodiploidy is unlikely to be a viable genetic strategy in populations which depend upon heterozygosity because deleterious recessives are exposed to the full force of selection in hemizygous males; thus, there is an initial bias in haplodiploid lineages to viscous population structures simply because haplodiploid populations are more likely to persist if they arise from inbreeding progenitors.

Secondly, a viscous population structure may predispose the species towards speciation. The genetic variance is decentralized among many semi-isolated populations; evolutionary change can benefit from the combined action of drift and selection. Furthermore, since populations are already semi-isolated, gene flow can be interrupted relatively easily. This process of speciation would normally be offset by local extinction due to inbreeding effects. However, in haplodiploids deleterious mutations are screened at each generation in the haploid male. Thus, there is virtually no limit on the degree of inbreeding such populations can support.

These sorts of considerations may explain the host distribution of the Oxyurida. In groups in which they occur pinworms tend to be very common. Each host species commonly has its own parasite species and many host species (e.g. among diplopods, passalid beetles, mole crickets, and tortoises) may harbor several parasite species, often members of the same genus or subfamily. This suggests that pinworms are often more prone to speciation than their hosts. This is not surprising in light of the extremely localized transmission patterns that exist in pinworms; in most pinworms of mammals the focus of transmission is the infected host itself. The egg is not terribly resistant and the parasite is dependent on host movements for dispersal. 
Minor barriers that separate host populations may prove impassible to their parasites.

Pinworms are among the most ancient parasitic nematode lineages and have undergone repeated radiations in successive host groups. However, their life cycle remains remarkably constant throughout. They have been adept in colonizing phylogenetically unrelated hosts, but only when these hosts fall into the required ecological mold - they must be saprophagous or omnivorous with a rich bacterial flora in the posterior gut. Pinworms have never invaded the tissues of their hosts, nor have they invaded other sites in the gut; intermediate hosts are unknown. Perhaps the same factors that facilitate speciation in this group (highly structured populations with its concomitant inbreeding) discourage the sorts of major inovative evolutionary change that characterizes the Strongylida, Spirurida and Ascaridida.

\section{REFERENCES}

Adamson M. L. : Studies on gametogenesis in Gyrinicola batrachiensis (Walton, 1929) (Ox=yuroidea; Nematoda). Can. J. Zool., 1981a, 59, 1368-1376.

Adamson M. L. : Seasonal changes in populations of Gyrinicola batrachiensis (Walton, 1929) in wild tadpoles. Can. Zool., 1981b, 59, 1377-1386.

Adamson M. L. : L'haplodiplö̈die des Oxyurida : incidence de ce phénomène dans le cycle évolutif. Ann. Parasitol. Hum. Comp., 1984, 95, 387-413.

Adamson M. L. : Modes of transmission and evolution of life histories in the zooparasitic Nematoda. Can. J. Zool., 1986, 64, 1375-1384.

Adamson M. L. : Evolutionary biology of the Oxyurida (Nematoda): Biofacies of a haplodiploid taxon. Adv. Parasitol., 1989a, $28,175-228$.

Adamson M. L. : Constraints in the evolution of life histories in zooparasitic Nematoda. In: Current Concepts in Parasitology. Edited by R. C. Ko. Hong Kong. University Press, Hong Kong, 1989b, 221-253.

Adamson M. L., Clease D. F. : Shape changes during in ovo development of thelastomatoid (Oxyurida; Nematoda). J. Parasitol., 1989, 75, 728-734.

Adamson M. L., Nasher A. K. : Pharyngodonids (Oxyuroidea: Nematoda) of Agama adramitana in Saudi Arabia with notes on Parapharyngodon. Can. J. Zool., 1984, 62, 2600-2609.

Adamson M. L., Nasher A. K. : Pharyngodonidae (Oxyuroidea: Nematoda) of Agama yemenensis in Saudi Arabia; hypothesis on the origin of pharyngodonids of herbivorous reptiles. System. Parasitol., 1985, 6, 299-318.

Anderson R. C. : The origins of zooparasitic nematodes. Can. J. Zool., 1984, 62, 317-328.

Borgia G. : Evolution of haplodiploidy; models for inbred and outbred systems. Theoret. Popul. Biol., 1980, 17, 103-128.

Gould S. J.: Ontogeny and phylogeny. Belknap Press, Harvard University Press, Cambridge, Mass., 1977, 501 p.

Hamilton W. D. : Extraordinary sex ratios. Science, 1967, 156, 477-488.

Hugot J. P., Bain O., Cassone J. : L'insémination traumatique et tube de ponte chez l'Oxyure du Lapin domestique. C. $R$. Acad. Sc. (Paris), 1982, 294, 707-710.

Hugot J. P. : L'insémination traumatique chez les Oxyures de Dermoptères et de Leporidés. Étude morphologique comparée. Considérations sur la phylogénèse. Ann. Parasitol. Hum. Comp., 1984, 59, 379-385.

Hugot J. P. : Sur le genre Auchenacantha (Oxyuridae; Nematoda) parasites de Dermoptères. Étude de la morphologie et de la distribution des formes. System. Parasitol., 1986, 8, 243-266.

Inglis W. G. : Allopatric speciation in the nematode parasites of frogs in southern. West. Aust. J. Zool. (London), 1968, 156, 405-513.

Inglis W. G. : Speciation in parasitic nematodes. Adv. Parasitol., 1971, 9, 185-223.

Petter A. J., Quentin J. C. : Keys to the genera of the Oxyuroidea. In: $\mathrm{CIH}$ Keys to the nematode parasites of vertebrate (R. C. Anderson, A. G. Chabaud and S. Willmott, eds), No. 4, pp. 1-30. Commonwealth Agricultural Bureaux, Farnham Royal, Slough, England, 1976.

White M. J. D.: Animal Cytology and Evolution. Third Edition. University Press, Cambridge, 1973, $961 \mathrm{p}$.

Zervos S. : Population dynamics of a thelastomatid nematode of cockroaches. Parasitology, 1988a, 96, 353-368.

Zervos S. : Evidence for population self-regulation, reproductive competition and arrhenotoky in a thelastomatid nematode of cockroaches. Parasitology, 1988b, 96, 369-379. 